of the baby are impossible to carry out. Nevertheless, all the indications are that the practice is nearly always, in hot countries or cold, unnecessary and undesirable. Newborn babies often need frequent body contact and always require abundant opportunities to suckle. Their mothers, no less, need support and encouragement, as is recommended by the authors of the study.

\section{Michael GURNEY}

World Health Organisation,

Regional Office for the

Alexandria, Egypt

' Laupus, W E, in Nelson Textbook of Pediatrics, ed V C Vaughan and R J McKay. 10th edn, p 164. Philadelphia, Saunders. 1975 .

Newton, M, American fournal of Clinical Nutrition, 1971, 24, 987 .

Applebaum, $\mathrm{R}$ M, Pediatric Clinics of North America,

\section{Encouraging breast-feeding}

SIR,-The recent papers by Dr E Eastham and others (7 February, p 305) and Drs C J Bacon and J M Wylie (p 308) have focused attention on the problem of breast-feeding, and attempts have been made to determine what influences a mother's decision to breastfeed her baby.

At Fazakerley Maternity Hospital in Liverpool (approximately 3500 deliveries a year), where many of the patients are from the lower socioeconomic groups, the proportion of mothers breast-feeding had fallen to $10 \%$ in October 1975 . Efforts to remedy this included a short questionnaire, designed to be answered in a "yes/no" manner, given randomly to women who had just been delivered. Only 65 usable replies were received, making detailed analysis impossible; nevertheless, a broad area of ignorance was highlighted.

The results obtained mirror those from more exhaustive surveys. When they came into hospital only 13 of the 65 mothers hoped to breast-feed their babies. Thirty-three would have liked more advice and plainly this had not been available to them from medical sources in an understandable form, if at all. Only one patient had received any instruction from her general practitioner, other sources being the antenatal clinic (6) parentcraft class (7), relaxation class (10), the patient's mother or another relative (26), or a women's magazine (10). Of the 13 patients hoping to breast-feed, 12 wanted more advice; 21 others intending to feed their babies artificially were potential "converts" had they received more advice. The need to return to work, often assumed to be a significant factor, seemed to be irrelevant, as only three mothers stated that they would be returning to a full-time paid job within three months.

Patently a great deal more could be done in the antenatal period. The opportunity to attend parentcraft classes is open to all patients, but the minority who do so seem to represent disproportionately the higher socioeconomic groups, many of whom already intend to breast-feed. At Fazakerley Hospital, finances permitting it is intended to have a continuous running audiovisual projection unit in the clinic waiting area providing breast-feeding propanganda, but at best this can only give limited information, though it is hoped that it will stimulate interest.

In a utopian obstetric service infant feeding would be discussed individually with every patient early in the pregnancy and advice would always be readily available; but in a busy clinic in reality there is not the time available. Perhaps there is a role for the paediatrician in the antenatal period at least to interview every primipara.
Fundamentally, however, the problem is one of changing irrational social attitudes to breast-feeding. Should not those concerned with infant welfare be going to the secondary schools and explaining sensible feeding practices to the potential parents (mothers and fathers) of a few years hence?

Alder Hey Children's Hospital,
Liverpool

J G Davies

Bottle-feeding

SIR,-Drs B A Wharton and $\mathrm{H} M$ Berger (29 May, $p$ 1326) begin their article on bottlefeeding: "Whenever possible mothers should be encouraged to breast-feed their babieseven as little as two weeks is valuable." That pathetic "two weeks" aside, when is it no possible to encourage breast-feeding? Did they not mean "When there is no contraindication"? And how often is there a contraindication, as distinct from a culturally determined unwillingness to breast-feed, a conditioning doctors and nurses at wors take part in and at best commonly ignore? There is no mention in the article of the effect of the practice of some maternity hospitals of supplying mothers with preformulated feeds. And neither in this article nor in the preceding article by Dr D P Addy (22 May, $p$ 1268) was there any detailed discussion of how to induce mothers to breast-feed, and this despite the many major advantages, some of them lifelong, detailed in Dr Addy's article.

The bottle-feeding article was obviously wellintentioned and most accurate; but it would need another article to comment on it adequately. I will make only four points. Firstly, sterilisation of bottles and teats by boiling: the description of this is daunting indeed. No wonder diarrhoea in bottle-fed babies is common, and in underdeveloped countries often fatal.

Secondly, making up the feed: although Drs Wharton and Berger do commend the 1974 Repor of the DHSS Working Party, ${ }^{1}$ they do not mention the fact, which seven expert members of the working party acknowledged ${ }^{2}$ some months after the report appeared, that they themselves had used for the analyses quoted in their tables in the report a 1 in 8 dilution of National Dried Milk as against the 1 in 10 to 1 in 12 recommended on the NDM pack. Their report stated, as regards the making-up of feeds, "it is not only mothers who make mistakes. . . Nurses and midwives as well as mothers were inaccurate, and all erred usually on the side of over-concentration." They could by their own admission have added "and the country's leading experts on baby feeding." In this contex the working party's indication that NDM had for years contained undesirable excess of sodium and phosphate was almost an irrelevant detail.

Thirdly, Drs Wharton and Berger state that "infant formulae based on unmodified cows" milk with added vitamins and iron were used for 30 years or more before the dangers of too much vitamin $\mathrm{D}$ or too much sodium were fully realised." With that background and the defects of NDM as a donnée, might it not be advisable to proceed most cautiously with any further modificatio of artificial feeds? And yet we read a little later, in connection with the missing anti-infective properties of such feeds, that "possibly by geneti selection a cows' milk containing larger amount of lactoferrin might be developed" and "experiments are already being made to produce cows" milk rich in immunoglobulins by immunisin cows with appropriate organisms." As we currently have some 600000 births a year and so could have available a plethora of human milk with all its highly beneficial qualities, why bother immunising the cows? And are they not to be given a feed with a formaldehyde-casein coating to increase the polyunsaturated fat content of the milk, and so ring it even more into line with human milk ?3

Fourthly, I found no mention anywhere in the article of the practice in underdeveloped countries, encouraged by the West, of giving up breastfeeding in favour of bottle-feeding; and yet the $B M F$ is read widely in such countries. A recent official estimate ${ }^{4}$ for the number of children in the world suffering from malnutrition due to the decline in breast-feeding was $200 \mathrm{~m}$ (sic). I think of bottle sterilisation and scoops and of an illiterate African woman with no running water and an open fire paying one-third of her husband's wage for the milk powder, which she therefore over-dilutes with the obvious consequences; and of a Western baby, obese from his over-concentrated feeds.

The article by Drs Wharton and Berger, and indeed our whole attitude to breastand bottle-feeding, remind me of what was said very recently about obstetric delivery today: "Experience has shown that labour is far from safe if left to the capricious whims of Nature." Substitute "infant feeding" for "labour" and the sentence seems to express exactly the sentiments of much of the Western medical establishment towards breast-feeding. If the human body cannot teach us the dangers of interfering overmuch with the capricious whims of Nature, surely what we have done in the last 30 years to the ecosphere might. But then we doctors often wear blinkers. It was not by chance that it was a layman ${ }^{6}$ who uttered recently what has for some time been a truism: that "The medical establishment has become a major threat to health."

JOHN S BRADSHAW

How Caple

'Department of Health and Social Security, Present Day Practice in Infant Feeding, Reports on Health and Social Subjects No 9. London, HMSO, 1974. "Arneil, G C, et al, Lancet, 1975, 1, 450.

3 Lancet, 1975, 2, 960

Food and Agriculture Organization of the United Nations: The State of Food and Agriculture 1974. Rome, FAO, 1975.

Beard, R W, and Chamberlain, G, Lancet, 1976

Illich, I, Limits to Medicine, p. 3. London, Marion Boyars, 1976

\section{Alcohol and the brain}

SIR,-In your leading article on this subject (15 May, p 1168) you were kind enough to quote the air encephalographic, psychometric, and electroencephalographic study of alcoholic cerebral atrophy written by Dr Lance Perrett and myself.' I would like to add a few comments in the light of recent developments in the diagnosis of brain disorders.

Our own study relied on relatively simple psychometric tests such as the Wechsler Adult Intelligence Scale and the Benton Visual Retention Test. Even so there was a significant correlation $(\mathbf{P}<0.01)$ between these tests and the degree of cortical atrophy. More accurate and informative psychometric tests are available in the shape of the HalsteadReitan test battery," and the advent of the EMI-Scanner means that information about the state of the cortex and ventricles can now be obtained painlessly. The delineation of the cortex by the EMI-Scanner is possibly a little less precise than that provided by air encephalography, but may well be adequate for most purposes." Most studies, including ours, have found the EEG to be singularly unhelpful in the diagnosis of alcoholic brain damage.

I support your view that a combination of 